\title{
A STUDY OF BIPEDICLE FLAPS FOR POST BURN CONTRACTURE
}

\author{
Somashekhar Samagandi ${ }^{1}$, Shekappa C. Malagimani ${ }^{2}$
}

\section{HOW TO CITE THIS ARTICLE:}

Somashekhar Samagandi ${ }^{1}$, Shekappa C. Malagimani. "A Study of Bipedicle Flaps for Post Burn Contracture". Journal of Evolution of Medical and Dental Sciences 2014; Vol. 3, Issue 09, March 3; Page: 2340-2347, DOI: $10.14260 /$ jemds/2014/2144

INTRODUCTION: Post burn scarring and contracture resulting in functional limitation and aesthetic disfigurement, remains the most frustrating complication of burn wound healing. This study is under taken to know the efficacy of bipedicle flaps in management of post burn contractures, which make use of the unaffected skin or healed suppled skin over the critical areas there by decreasing the recurrence of contracture and also decreasing the duration of post-operative splintage. The functional results are impressive and aesthetic results are satisfactory in the overall long term assessment.

KEYWORDS: Burn scar, burn contracture, bipedicle flaps, aesthetic.

\section{AIMS AND OBJECTIVES:}

1. Evaluation of etiopathogenesis of post burn contractures in current day scenario of patients attending a major tertiary level burn center in teaching institute.

2. To study the efficacy of bipedicle flaps in the management of post burn contractures across the critical joints of the victims.

3. To assess the functional and aesthetic results of bipedicle flaps in the management of post burn contractures

REVIEW OF LITERATURE: McDonald and Deitch ${ }^{1}$ (1987) did a prospective analysis of variables leading to hypertrophic scars and found that graft performed within 14 days of injury had lower incidence of hypertrophic scarring compared with those done after 14 days of post burn. Compression therapy was introduced by Larson et $\mathrm{al}^{2}$ in 1971 . Cronin ${ }^{3}$ (1957) made a major breakthrough in burn reconstruction. He described a two piece full contact custom made splint from horsehide wool felt, silastic and final layer of horsehide. The split was worn continuously for 6 months. The importance of modern splinting techniques was documented by Bunchman ${ }^{4}$ (1975) from a series of patients treated at Galveston Shrine Burn Institute. He noted that $84 \%$ of patients with full thickness burns treated before 1968 developed neck contractures, but only $51 \%$ of patients treated after 1968. The change in treatment was because of the use of a full contact orthoplast neck conformer early in treatment. Neale et $\mathrm{al}^{5}$ (1993) used 52 tissue expanders in 37 pediatric patients for face and anterior neck burn resurfacing. Contracting scars can frequently be corrected with single or multiple z plasties. If the surrounding scar is not right, a four flap Z platy by Wolf and Broad Bent, a six flap Z plasty by Mir-y-Mir ${ }^{6}$ and five flap procedure by Hirshowtz ${ }^{7}$ have been used for the same purpose with good results. Stern et $\mathrm{al}^{8}$ (1987) classified the severity of contractures of the PIP joints in children with palmar burns. Dias $\mathrm{AD}^{9}(1983)$ did study of bipedicle flaps in the correction of burn contractures. The study involves 38 contracture of various joints in 32 patients. Study showed impressive functional results and the satisfactory cosmetic results. 
MATERIALS AND METHODS: The study of 28 cases of bipedicle flap in management of post burn contractures was carried out by the Plastic Surgery Dept. in the hospitals attached to teaching institute during a period from Feb 2009 to July 2011 (two and half years). Out of all, post burn contractures who attended OPD, only those who were admitted and managed with operative procedures were included in the study. In preoperative period. All patients were admitted before operation. All routine blood investigations done. X-rays of affected parts taken in all cases. Photographs were obtained before surgery. Soft tissue deficiency calculated before surgery.

PROCEDURE: Bipedicle flap was done in the following manner. General or regional anesthesia was given depending on site of contracture. After positioning, markings were done for release of contracture by bipedicle flap technique i.e. first joint axis was marked, then two transverse incisions are marked. Incision taken along the markings, deepened till the sub scar soft tissue is seen. Contracture released step by step on either side of skin paddle or (scar) healed suppled skin which was preserved in between the releasing incisions. Skin paddle kept on critical area was not elevated from bed so as to preserve the vascularity. The dimensions of created raw areas were noted and similar amount of skin graft was harvested. The split thickness skin graft was obtained in most of cases from the available donor areas. The full thickness graft obtained from groin in two cases of neck contracture for coverage of raw area over cervicomandibular area. The graft was sutured with 4-0 ethilon with continuous suture and pressure dressings given in usual manner. Splintage was given with pop slab in the position of maximum contracture release. The same position was maintained in ward during post-operative days.

Post-operative period: Antibiotics were given to every patient intraoperatively and continued for 10 days. The first dressing was done on $7^{\text {th }}$ or $8^{\text {th }}$ day at bed side and graft take was noted, later on dressing was done alternate day till raw areas healed completely. The custom made pressure garment and splints was used once graft settled well, for period of one year. When the grafts have become stable, active exercises is begun. The patients were discharged after obtaining pressure garments and splints with advice on care of the grafted area, donor area and were asked strictly to use the pressure garments 24 hours a day for a minimum period of year.

OBSERVATIONS: The study includes 28 cases of post burn contracture at various joints which are managed by bipedicle flaps (some cases by 2-bipedicle flaps) and skin grafting. The following observations were made. The total number of admissions to plastic surgery department in all hospitals attached to teaching institute during period between Feb 2009 and July 2011 is 2923. Among these, the post burn contractures at various joints attributed to 230 cases (7.8\%). This percentage of cases doesn't include the post burn deformities i.e. post burn ear deformity, post burn eyelid deformity etc.

The study of bipedicle flap technique was under taken in 28 cases, among these post burn contracture across the various joints. 


\begin{tabular}{|c|c|c|}
\hline Nature of Burns & No. of Cases & Percentage (\%) \\
\hline Flame & 26 & 92.8 \\
\hline Electrical & 1 & 3.6 \\
\hline Scalds & 1 & 3.6 \\
\hline Total & 28 & 100 \\
\hline
\end{tabular}

TABLE NO. 1: FREQUENCY ACCORDING TO NATURE OF BURNS

\begin{tabular}{|c|c|c|}
\hline Sex & No. of Cases & Percentage (\%) \\
\hline Male & 10 & 35.7 \\
\hline Female & 18 & 64.3 \\
\hline Total & 28 & 100 \\
\hline
\end{tabular}

TABLE NO. 2: SEX DISTRIBUTION

The male to female ratio in our study found 2:3.6.

\begin{tabular}{|c|c|c|}
\hline Age In Years & No. of Cases & Percentage (\%) \\
\hline $0-10$ & 1 & 3.6 \\
\hline $11-20$ & 9 & 32.2 \\
\hline $21-30$ & 13 & 46.4 \\
\hline $31-40$ & 4 & 14.2 \\
\hline $41-50$ & 1 & 3.6 \\
\hline$>50$ & - & - \\
\hline Total & 28 & 100 \\
\hline \multicolumn{2}{|r|}{ TABLE NO. 3: AGE DISTRIBUTION } \\
\hline
\end{tabular}

In 28 randomly selected cases for bipedicle flap technique, maximum cases were found in age group of 21-30 year (46.4\%).

\begin{tabular}{|c|c|c|}
\hline Site & No. of Cases & Percentage (\%) \\
\hline Neck & 10 & 35.7 \\
\hline Axilla & 5 & 17.8 \\
\hline Elbow & 4 & 14.3 \\
\hline Wrist & - & - \\
\hline Finger & 6 & 21.4 \\
\hline Groin & 1 & 3.6 \\
\hline Knee & 1 & 3.6 \\
\hline Ankle & 1 & 3.6 \\
\hline Toe & - & - \\
\hline Total & 28 & 100 \\
\hline
\end{tabular}

\section{TABLE NO. 4: SITE OF CONTRACTURE RELEASE}

The technique was used maximum for neck contractures (35.7\%), least in groin, knee and ankle joint contracture, one case each (3.6\%). 


\begin{tabular}{|c|c|c|}
\hline Severity & No. of Cases & Percentage (\%) \\
\hline Mild & 1 & 10 \\
\hline Moderate & 2 & 20 \\
\hline Severe & 6 & 60 \\
\hline Mentosternal adhesion & 1 & 10 \\
\hline Total & 10 & 100 \\
\hline
\end{tabular}

The bipedicle flap technique (some cases by 2 bipedicle flaps) was used in 6 cases (60\%) of severe neck contracture out of 10 neck contracture released by this technique.

\begin{tabular}{|c|c|c|c|}
\hline \multirow{3}{*}{ Site } & \multicolumn{2}{|c|}{ No. of Cases } & Method of Release \\
\cline { 2 - 4 } & 7 & Bipedicle flap \\
\hline \multirow{3}{*}{ Axilla } & 3 & 2-Bipedicle flaps \\
\cline { 2 - 4 } Elbow & 4 & Bipedicle flap \\
\hline \multirow{2}{*}{ Finger } & 4 & 8 & Bipedicle flap \\
\cline { 2 - 4 } & 14 contractures & 6 & 2-Bipedicle flaps \\
\hline Groin & 1 & & Bipedicle flap \\
\hline Knee & 1 & Bipedicle flap \\
\hline Ankle & 1 & Bipedicle flap \\
\hline
\end{tabular}

TABLE NO. 6: METHOD OF PEDICLE FLAPS

IN THE JOINT CONTRACTURE MANAGEMENT

Three cases of neck contracture among 10 were released by 2-bipedicle flaps technique. One case of axillary contracture i.e. post axillary fold only was released by X-plasty with advancement of two triangular flaps (having normal skin).

In 6 patients of 14 finger contractures, 8 contracture were released by single bipedicle flap technique and remaining 6 by 2-bipedicle flaps technique.

\begin{tabular}{|c|c|c|}
\hline Period & No. of Cases Followed & Complications \\
\hline 6 months & 26 cases $(92.8 \%)$ & - \\
\hline 1 year & 23 cases $(82.1 \%)$ & Donor area hypertrophy in one case \\
\hline 2 year & 20 cases $(71.4 \%)$ & - \\
\hline \multicolumn{2}{|c|}{ TABLE NO. 7: FOLLOW UP AND COMPLICATIONS IN THE LATER PERIOD }
\end{tabular}

In our prospective study of 28 cases within study period of two and half year. 26 cases (92.8\%) were followed for period of 6 months, 23 cases $(82.1 \%)$ for period of 1 year and 20 cases $(71.4 \%)$ were followed for period of 2 year. During the follow up, cases were examined for evidence of recurrence of the contracture, and donor area problems. Patients are asked about the fitting of 
pressure garments and splint. Patient's satisfaction was enquired in all cases. In one case of elbow contracture donor area hypertrophy was found after one year, which was treated with pressure garment. None of the patients showed recurrence of the contracture. Most of the patients used the splintage and pressure garment for a year, however 2 cases of neck contracture refused the cervical collar but no recurrence was found in these cases.

\begin{tabular}{|l|c|c|}
\hline \multicolumn{3}{|c|}{ A. Functional Results } \\
\hline Functional Results & No. of cases & Percentage \\
\hline Excellent & 18 & $64.2 \%$ \\
\hline Good & 6 & $21.4 \%$ \\
\hline Fair & 1 & $3.6 \%$ \\
\hline Poor & 1 & $3.6 \%$ \\
\hline \multicolumn{3}{|c|}{ B. Aesthetic Results } \\
\hline Aesthetic results & No. of cases & Percentage \\
\hline Excellent & 12 & $42.8 \%$ \\
\hline Good & 10 & $35.7 \%$ \\
\hline Fair & 3 & $10.7 \%$ \\
\hline Poor & 1 & $3.6 \%$ \\
\hline TABLE NO. 8: PATIENTS PERCEPTION OF RESULTS
\end{tabular}

Within the long term follow period. The functional results were excellent in 18 cases (64.2\%) and good in 6 cases $(21.4 \%)$. The functional results are evaluated in the form of range of motion. The aesthetic results were excellent in 12 cases (42.8\%) and good in 10 cases (35.7\%). In one case (3.6\%) aesthetic result was poor which was due to hypopigmented scar.

DISCUSSION: In this study, 28 cases of post burn contracture at various joints managed by bipedicle flaps (some cases by 2-bipedicle flaps) and grafting at the hospitals attached to teaching institute are included.

The bipedicle flap technique was most commonly used in contractures due to flame burn. Technique was least commonly used in contractures due to electrical and scald burns. The maximum number of cases (13 cases - 46.4\%) were in age group of 21-30 year and male to female ratio in our study was found to be 2:3.6, where as in study conducted by Dias AD maximum number of cases were in age group of 21-40 year (13 cases) and sex distribution was equal. In our study, the technique was employed in maximum number for the post burn contracture of neck that is 10 cases $(35.7 \%)$ out of 28.

Our study also include 2-bipedicle flaps technique which was done for three post burn neck contractures. One case of axillary contracture was released by X-plasty and grafting which is almost similar to bipedicle flap technique. The 2-bipedicle flaps technique is also used in 6 finger contractures.

Among 10 cases of post burn neck contracture release, the technique employed for maximum number for severe deformity cases. The technique also employed in one case of mentosternal adhesion. In axillary contracture, the technique employed for maximum number of cases where in entire axilla was involved. In elbow contractures, the bipedicle flap technique was most commonly performed on major scar contractures. 
EL-Otefy M.A. studied 158 patients (48 male and 110 female) whose age ranged from $1 \frac{1}{2}$ to 60 years. The study include neck contractures (56 patients), axillary contracture (17 patients), elbows finger, groin and popliteal space (83 patients), and pre patellar scar (2 patients). 125 Patients out of 158 patients treated by X-plasty and skin grafting. The technique used is X shaped incision rather than linear incision. The two ' $\mathrm{V}$ ' shaped flaps separated by transverse incision may be joined by a vertical component, if the local condition warrants it. The study showed consistently satisfactory results and only two contractures required revision. In our study X-release was used in only one contracture (i.e. axilla) with good result.

The use of splints and continuous pressure garments across the joints has been effective in minimizing hypertrophy, scar contracture and recurrence of contracture, the true efficacy remains undefined.

In our study, the functional results are excellent in 18 cases (64.2\%) and good in 6 cases (21.4\%) of the followed patients. This is because of bipedicle flap at the critical (joint) area and tension of the contracting scar is broken at multiple levels. The aesthetic results were excellent in 12 cases $(42.8 \%)$ and good in 10 cases $(35.7 \%)$ patients of the followed patients as color match was fairly equal to the surrounding scar.

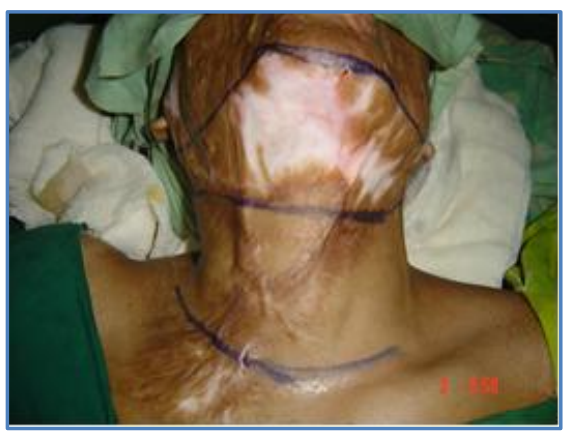

Fig-1: Markings

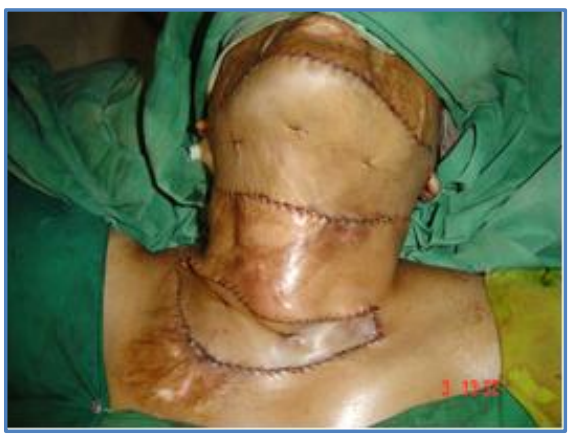

Fig-3: Post Operative

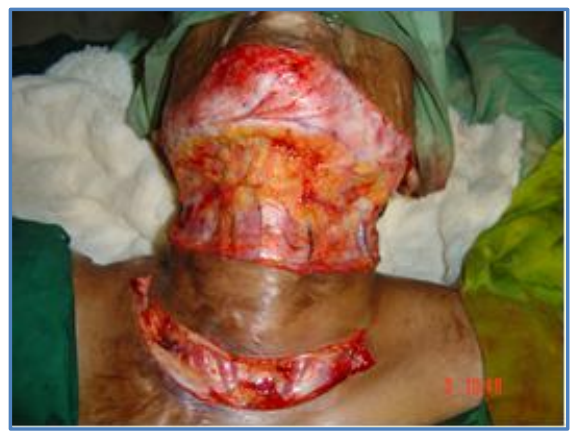

Fig-2: Release of scar

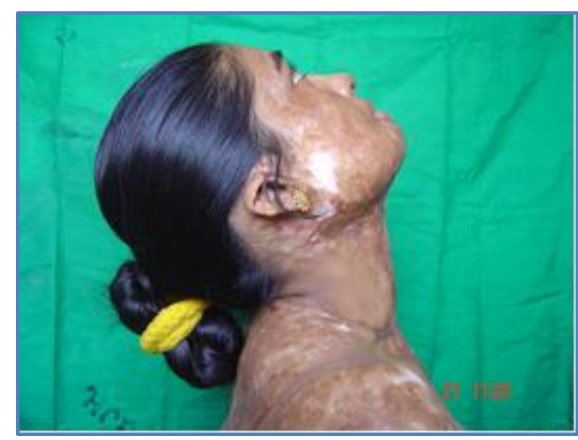

Fig-4: Result 


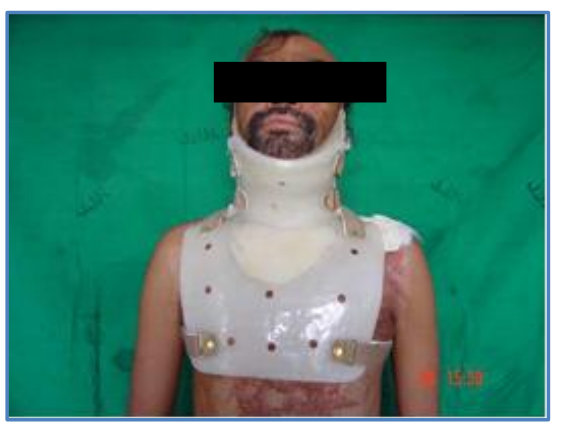

Fig-5: Spintage

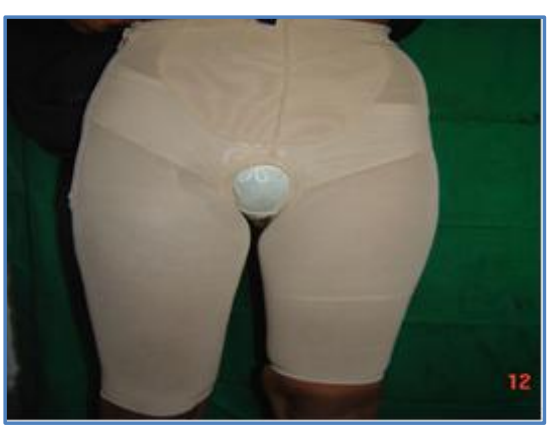

Fig-6: Pressure garment

\section{CONCLUSIONS:}

- The bipedicle flap technique in the management of post burn contractures is a versatile method.

- The technique can be applied across all joints contracture.

- The functional results of the technique are excellent and cosmetic results are satisfactory.

- The advantage of the technique is the presence of a flap across the critical part of contracture. It decreases the tendency to post-operative recurrence of the contracture and need for prolonged splintage.

- The 2-bipedicle flaps technique can be employed in some selected cases with excellent scar maturation with moderate aesthetic results.

\section{BIBLIOGRAPHY:}

1. McDonald WS, Deitch EA. Hypertrophic skin grafts in burned patients: A prospective analysis of variables. J. Trauma 1987; 27: 147-150.

2. Larson DL et al. Techniques for decreasing scar formation and contractures in the burned patient. J. Trauma 1971; 11: 807-823.

3. Cronin TD. The use of a molded splint to prevent contracture after split skin grafting on the neck. Plast. Reconst. Surg. 1961; 27: 7-18.

4. Bunchman $\mathrm{HH}$ et al. Prevention and management of contractures in patients with burns of the neck. Am. J. Surg. 1975; 130: 700-703.

5. Neale HW, Krutzman LC, Goh KBC, Billmire DA, Yakuboff KP, Warden G. Tissue expanders in the lower face and anterior neck in pediatric burn patients: limitations and pit falls. Plast. Reconst. Surg. 1993; 91 (4): 624-631.

6. Mir Y Mir Z. The six flap Z plasty. Plast. Reconstr. Surg. 1973; 52: 625.

7. Hirshowitz B, Karev A, Leuy Y. A five flap procedure for axillary webs leaving the apex intact. Br. J. Plast. Surg. 1977; 30: 48.

8. Stern PJ, Neale NW, Graham TJ, Warden GD. Classification and treatment of interphalangeal joint flexion contractures in children. J. Hand Surg. 1987; 12 (A): 450-457.

9. Dias AD. A bipedicle flaps in the correction of burn contractures. Br. J. Plast. Surg. 1983; 36: 5659. 


\section{ORIGINAL ARTICLE}

\section{AUTHORS:}

1. Somashekhar Samagandi

2. Shekappa C. Malagimani

\section{PARTICULARS OF CONTRIBUTORS:}

1. Associate Professor, Department of Plastic Surgery, VIMS, Bellary.

2. Associate Professor, Department of Surgery, VIMS, Bellary.

\section{NAME ADDRESS EMAIL ID OF THE} CORRESPONDING AUTHOR:

Dr. Shekappa C. M,

B/24, Staff Quarters,

VIMS (OPD) Contonment,

Bellary.

E-mail: doc_shekar@yahoo.com

Date of Submission: 01/02/2014.

Date of Peer Review: 03/02/2014.

Date of Acceptance: 11/02/2014.

Date of Publishing: 01/03/2014. 